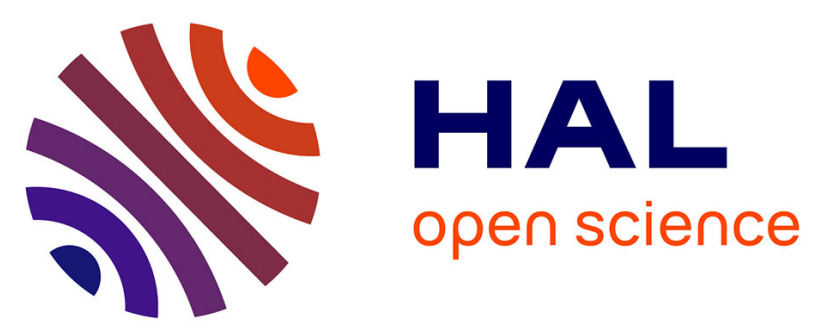

\title{
Development and Validation of the French Achievement Goals Questionnaire for Sport and Exercise (FAGQSE)
}

François Riou, Julie Boiché, Julie Doron, Ahmed Jérôme Romain, Karine Corrion, Gregory Ninot, Fabienne d'Arripe-Longueville, Christophe Gernigon

\section{- To cite this version:}

François Riou, Julie Boiché, Julie Doron, Ahmed Jérôme Romain, Karine Corrion, et al.. Development and Validation of the French Achievement Goals Questionnaire for Sport and Exercise (FAGQSE). European Journal of Psychological Assessment, 2012, 28 (4), pp.313-320. 10.1027/1015-5759/a000112 . hal-01580327

\section{HAL Id: hal-01580327 \\ https://hal-insep.archives-ouvertes.fr/hal-01580327}

Submitted on 1 Sep 2017

HAL is a multi-disciplinary open access archive for the deposit and dissemination of scientific research documents, whether they are published or not. The documents may come from teaching and research institutions in France or abroad, or from public or private research centers.
L'archive ouverte pluridisciplinaire HAL, est destinée au dépôt et à la diffusion de documents scientifiques de niveau recherche, publiés ou non, émanant des établissements d'enseignement et de recherche français ou étrangers, des laboratoires publics ou privés. 


\title{
Development and Validation of the French Achievement Goals Questionnaire for Sport and Exercise (FAGQSE)
}

\author{
François Riou ${ }^{1}$, Julie Boiché ${ }^{1}$, Julie Doron ${ }^{1}$, Ahmed-Jérôme Romain ${ }^{1}$, \\ Karine Corrion ${ }^{2}$, Grégory Ninot ${ }^{1}$, Fabienne d'Arripe-Longueville ${ }^{2}$, \\ and Christophe Gernigon ${ }^{1}$
}

\author{
${ }^{1}$ Laboratory Epsylon, EA 4556, Dynamics of Human Abilities \& Health Behaviors, University of \\ Montpellier \& St Etienne, France, ${ }^{2}$ Laboratory LAMHES, University of Nice Sophia-Antipolis, Nice, France
}

\begin{abstract}
Recently, Elliot and Murayama (2008) pointed out a number of theoretical and methodological shortcomings among the instruments assumed to measure achievement goals. This research aimed to develop and validate a French Achievement Goals Questionnaire for Sport and Exercise (FAGQSE). In a first study, factor analyses conducted on a 20-item preliminary version supported the existence of four factors corresponding to the four types of goals of Elliot and McGregor's (2001) framework (mastery-approach, performance-approach, mastery-avoidance, and performance-avoidance). A second study examined a more parsimonious 12 -item version of the FAGQSE, which was found to be valid among samples of athletes, exercisers, and physical education students. The temporal stability of the questionnaire was evidenced by a satisfactory test-retest over a 1-month period, and its theoretical validity was supported by correlations between achievement goals and entity/incremental theories of sports ability, perceived sports competence, and sports anxiety. The FAGQSE is a valid and reliable French instrument for achievement goal motivation. This instrument can be used for theoretical and applied purposes in various sports and exercise settings.
\end{abstract}

Keywords: mastery-approach goal, performance-approach goal, mastery-avoidance goal, performance-avoidance goal, achievement motivation

Since the early 1980s, the construct of achievement goal has been considered to be at the core of the different achievement motivation theories. Authors first distinguished between two kinds of achievement goals: self-referenced and norm-referenced goals. When individuals pursue self-referenced goals, also called mastery goals (e.g., Dweck, 1986), they seek to master a task or to progress in mastering it. When they pursue norm-referenced goals, also called performance goals (e.g., Dweck, 1986), they seek to demonstrate more competence than others. In former achievement goals frameworks (Dweck, 1986; Nicholls, 1984), mastery goals were assumed to favor adaptive achievement patterns such as challenging task choices, greater effort, and persistence, regardless of perceived ability. Performance goals were assumed to lead to adaptive achievement patterns only when people are confident in their abilities to perform better than others; but these goals were seen as detrimental when people realize that their ability is not likely to be demonstrated. In this case, indi- viduals avoid challenging tasks and subsequently reduce their effort and persistence in the face of difficulty.

In recent refinements of achievement goal theory (Elliot \& McGregor, 2001), the mastery-performance dimension of goals was combined with the appetive versus aversive valence of the focal outcome, leading to a $2 \times 2$ achievement goal framework including mastery-approach, performance-approach, mastery-avoidance, and performanceavoidance goals. Mastery-approach goals correspond to aiming to perform a task well or to improve in performing that task. Performance-approach goals correspond to aiming to outperform others. Mastery-avoidance goals consist of focusing on not making mistakes or not doing worse than a previous performance. Performance-avoidance goals involve focusing on not being outperformed by others. Various motivational patterns have been found to result from the adoption of these different goals, with mastery-approach and performance-approach appearing most often as adaptive, and performance-avoidance appearing as the 
least adaptive (e.g., Elliot \& McGregor, 2001; see also Roberts, Treasure, \& Conroy, 2007, for a review in sports and exercise).

The growing interest regarding achievements goal theories of motivation urged researchers to develop questionnaires that can measure goals within specific achievement contexts. However, as Elliot and Murayama (2008) noticed, achievement goal conceptualizations were not always clear enough to provide a satisfactory guidance for how goals should be operationalized. Furthermore, when conceptualizations of goals were clear, the correspondence with their operationalization was often poor. The general critiques from Elliot and Murayama (2008) were that items assumed to tap achievement goals (1) sometimes fail to assess goals directly, (2) collapse together the goal (i.e., the aim) and the motive (i.e., the reason) underlying the goal, (3) are sometimes applicable to both mastery-based and performance-based goals, (4) pit one goal against another, and (5) include affective contents. Moreover, specific critiques concerned performance goals, namely, that performance-approach and performance-avoidance items sometimes differentially emphasize normative comparison and focus on extreme populations of potential winners or losers. As a result, the inadequacy of the measurement of goals undermines the quality of the interpretations of the empirical results of research on achievement motivation.

Those critiques are applicable to the research conducted in sports settings, either with the original English version of the $2 \times 2$ achievement goals questionnaire for sports (Conroy, Elliot, \& Hofer, 2003) or its translated versions such as Schiano-Lomoriello, Cury, and Da Fonséca's (2005) French version. On the one hand, both of these English and French questionnaires for sports need to be reconsidered in order to overcome the shortcomings addressed by Elliot and Murayama (2008). On the other hand, the only questionnaire that is devoid of these shortcomings (Elliot \& Murayama, 2008) addresses only the academic domain. Therefore, the present research develops and validates a French questionnaire measuring achievement goals in sports and exercise settings: the French Achievement Goal Questionnaire for Sport and Exercise (FAGQSE), which takes into account Elliot and Murayama's psychometric updates. A preliminary study aimed to create a pool of items intended to constitute the frame of the FAGQSE to be tested next. The first study examines the factorial structure of a preliminary 20-item version of the FAGQSE; the second study examines the psychometric qualities of a reduced version of the instrument across various populations, namely, adolescents in Physical Education (PE) courses, young adults involved in traditional individual or team sports, and middle/older adults who exercise in a structured context. More specifically, the factorial structure of a 12-item version of the FAGQSE as well as its reliability over time and its concurrent validity were tested among those populations.

\section{Study 1}

This study consisted of examining the factorial structure of a preliminary 20-item version of the FAGQSE as well as the internal consistencies of its subscales. The four-goal model (model A) - which is assumed to measure the four goals - was tested and compared to three alternative dimensional models. The first alternative model (Model B) was a trichotomous model in which performance-approach and performance-avoidance items were assumed to load on their respective latent factors, whereas mastery-approach and mastery-avoidance items were hypothesized to load together on a single mastery factor. Our attempt to merge mastery-approach and mastery-avoidance was based on the ambiguity of mastery-avoidance goals recently raised by Ciani and Sheldon (2010), who argued that mastery-approach items, as they are usually worded, may induce some misinterpretation among respondents who most often interpret them as reflecting an approach orientation. The second alternative model (Model C) was a mastery-performance model in which mastery-approach and mastery-avoidance items were expected to load together on a single mastery factor, whereas performance-approach and performanceavoidance items were assumed to load together on a single performance factor. Such a model was hypothesized because the literature usually reveals significant positive correlations between mastery-approach and mastery-avoidance goals and between performance-approach and performance-avoidance goals that are interpreted as stemming from the dimensions mastery or performance that features each of these pairs of goals (Elliot \& McGregor, 2001; Elliot \& Murayama, 2008). The third alternative model (Model D) was an approach-avoidance model in which mastery-approach and performance-approach items were expected to load together on a single approach-factor, whereas mastery-avoidance and performance-avoidance items were assumed to load together on a single avoidancefactor. Indeed, positive correlations were also found within these two pairs, these correlations being seen as the result of the common approach dimension of mastery-approach and performance-approach goals as well as the common avoidance dimension of mastery-avoidance and performance-avoidance goals (Elliot \& McGregor, 2001; Elliot \& Murayama, 2008).

\section{Method}

\section{Construction of a Preliminary Version}

A preliminary pool of items was created by translating and adapting items from Elliot and Murayama's (2008) Achievement Goal Questionnaire-Revised (AGQ-R) and by creating new items. An adhoc committee was specifically set up for this purpose and included researchers specialized in achievement motivation, teachers or coaches from near the three targeted populations, and bilingual peo- 
Table 1. Fit indices for the four competing models

\begin{tabular}{lccccccc}
\hline Models & $\chi^{2} / d f$ & NNFI & CFI & RMSEA & LO90 & HI90 & AIC \\
\hline A. Four-goal model & 2.93 & .98 & .98 & .084 & .076 & .093 & 612.2 \\
B. Trichotomous model & 3.12 & .97 & .98 & .088 & .080 & .097 & 647.4 \\
C. Mastery-performance model & 4.54 & .96 & .96 & .114 & .106 & .123 & 889.8 \\
D. Approach-avoidance model & 9.76 & .89 & .91 & .180 & .172 & .188 & 1771.7 \\
\hline
\end{tabular}

Notes. $n=272$. NNFI $=$ nonnormed fit index, $\mathrm{CFI}=$ comparative fit index, RMSEA $=$ root mean square error of approximation, LO90 $=$ Lower bound of the RMSEA's 90\% confidence interval, HI90 = Upper bound of the RMSEA's 90\% confidence interval, AIC = Akaike information criterion.

ple. Twelve items (i.e., three items per type of goal) were adapted from the AGQ-R. These items were translated into French and adapted to the field of sports and exercise by changing the words "students" and "learn" to the words "others" and "improve", respectively, and by removing any reference from the academic field. In case some of these 12 items did not survive the factorial analyses, eight items (two per type of goal) were added to prudently ensure a minimum of redundancy. These additional items were created based on the conceptual nature of the different achievement goals of Elliot and McGregor's $2 \times 2$ framework. As a result, a pool of 20 items was obtained, representing mastery-approach, performance-approach, mastery-avoidance, and performance-avoidance, with 5 items per subscale. Discussions and attempts to rephrase some items led the committee members to conclude that some mastery-avoidance items, especially those addressing competence as defined in intrapersonal terms (e.g., "My goal is to avoid doing worse than I usually do") would ever have complicated phrasings. Despite this difficulty, all items were retained for the next step of validation (see Appendix). It was expected that factor analyses would help eliminate the ambiguous items from this pool of 20 items.

\section{Participants}

A total of 272 undergraduates in sport sciences (182 males, 88 females, 2 unspecified; $M_{\text {age }}=20.4$ years \pm 2.52$)$, predominantly Caucasian and from a university in the south of France, voluntarily participated in the study intended to test the factorial structure of the 20-item version of the FAGQSE.

\section{Procedure and Measures}

The participants were enrolled at the beginning of small group regular courses. They were first ensured that their participation would remain anonymous and would in no way influence their course grade. Then, they answered the 20-item FAGQSE, using a 5-point Likert-type scale ranging from 1 (completely disagree) to 5 (completely agree).

\section{Data Analyses}

The different models were tested by structural equation modeling (SEM) using the AMOS 4 program. The analyses were processed on covariance matrices, and the solutions were generated on the basis of maximum-likelihood estimation. In the loading matrix, all error covariances were constrained to zero, whereas covariances between the latent factors were allowed. The fit indices for the different models were the $\chi^{2} / d f$ ratio, the comparative fit index (CFI), the nonnormed fit index (NNFI), the root mean square error of approximation (RMSEA), the RMSEA's 90\% confidence interval, and the Akaike information criterion (AIC). Cronbach's $\alpha$ were also calculated for all the subscales to account for their internal consistency. Following Kline's (2005) recommendations, the following criteria were used to evaluate the adequacy of the models with respect to the data: $\chi^{2} / d f<3.00 ; \mathrm{CFI}>.90 ; \mathrm{NNFI}>.90$; and RMSEA < .08. Moreover, as advocated by Chen, Curran, Bollen, Kirby, and Paxton (2008), the lower and upper bounds of the RMSEA's 90\% confidence interval should be lower than .05 and .1, respectively. The AIC index allows multiple models comparisons; the lower the value of AIC, the better the model is. Internal consistency was deemed good for coefficients $\alpha$ above .70 (Nunnally \& Bernstein, 1994).

\section{Results}

The fit indices related to the competing models are presented in Table 1. Whereas NNFI and CFI indices were good for all the models, only model A showed acceptable $\chi^{2} / d f$ ratio and RMSEA index. Moreover, model A displayed the lowest AIC index. However, while the upper bound of the RMSEA's 90\% confidence interval was good, the lower bound was above the advocated criterion of .05 . Despite this shortcoming, only model A could be considered a potential candidate to account for the factorial structure of the FAGQSE.

As shown in Table 2, high positive interfactor and interscale correlations were found between the two mastery goals and between the two performance goals, whereas a moderate positive correlation was found between the two avoidance goals. No significant correlation was found be- 
Table 2. Descriptive statistics, Cronbach's $\alpha$, and correlation matrix for the four factor model

\begin{tabular}{llcllll}
\hline Variable & $M$ & $S D$ & 1 & 2 & 3 & 4 \\
\hline Mastery-approach goals & 4.45 & .71 & $\mathbf{. 8 7}$ & & & \\
Performance-approach goals & 2.93 & 1.09 & $.00 / .02$ & $\mathbf{. 9 2}$ & $.06 / .09$ & $\mathbf{. 8 0}$ \\
Mastery-avoidance goals & 4.02 & .76 & $.90 * / .73^{*}$ & $.09 * / .68 *$ & $.33 * / .32 *$ & $\mathbf{. 8 8}$ \\
Performance-avoidancegoals & 3.10 & 1.02 & $.16 / .13$ & $.74 *$
\end{tabular}

Notes. $n=272$. Interfactor correlations are presented before the slash; Interscale correlations are presented after the slash; $* p<.05$. Bold values in the diagonal represent Cronbach's $\alpha$.

tween the two approach goals. The items loaded on their respective factors significantly $(p<.001)$ and highly, with coefficients $\beta$ ranging from .57 to .88 . Coefficients $\alpha$ revealed good internal consistencies for all the subscales $(.80$ $<\alpha<.92)$.

\section{Discussion}

Only the four-goal structure of the 20-item FAGQSE showed almost acceptable psychometric properties. The factors of this structure were not completely independent since the two mastery factors were highly correlated as were the two performance factors, whereas the two avoidance factors were moderately correlated. These relationships are consistent with those found in previous research (Elliot \& Murayama, 2008) and result from the fact that some pairs of goals share either the same definition of competence or the same valence.

Although our data fit the four-goal model acceptably, improvements remain necessary, at least to decrease the lower bound of the $90 \%$ confidence interval of the RMSEA. It would also be useful to reduce the number of items so that the questionnaire can be completed more easily and quickly. Moreover, because sports and physical activities are practiced differently by different populations, the factorial structure of the FAGQSE needs to be tested across different settings and populations. Finally, the reliability of the instrument over time as well as its theoretical validity should also be tested.

\section{Study 2}

This second study (a) tests the 4-factor structure of a reduced version of the FAGQSE across various samples of individuals who are involved in different kinds of sports or exercise activities; (b) examines the test-retest reliability of the questionnaire over a 1-month period; and (c) tests the concurrent validity of this version, based on its relationships with constructs known to be associated with achievement goals such as implicit theories of ability (Dweck \& Leggett, 1988), perceived competence, and anxiety. Indeed, research conducted in PE showed that an incremental theory of ability (i.e., belief that competence is malleable) positively predicted mastery goals whereas an entity theory of ability (i.e., belief that competence is fixed) positively predicted performance goals (Corrion et al., 2010). In sports, perceived competence was found to positively predict approach goals and negatively predict avoidance goals (Cury, Da Fonséca, Rufo, \& Sarrazin, 2002). In academics, anxiety prior to an exam was found to positively relate to performance goals (McGregor \& Elliot, 2002).

\section{Method \\ Participants}

This study was carried out among three samples of sports or exercise practitioners corresponding to young adult athletes, high school PE students, and middle/older age exercisers. The athletes sample included 270 sports sciences students $\left(173\right.$ males and 87 females; $\left.M_{\text {age }}=21.0 \pm 2.44\right)$. The PE students sample included 255 students from a junior high school and a senior high school in southern France. They were in 8th, 9th, and 10th grades (138 males and 116 females; $\left.M_{\text {age }}=14.8 \pm 0.96\right)$. The exercisers sample - here, a sample clearly older than the others which included mainly females, as is typical of this population in France - included 234 adults recruited in six associations (26 males and 208 females; $M_{\text {age }}=66.0 \pm 11.78$ ). They practiced various types of moderate physical activities including gymnastics, step, and stretching, and exercised from $1-4 \mathrm{~h}$ a week $(M=1.9 \mathrm{~h})$.

\section{Procedure}

For every sample, the conditions of recruitment of the participants, the ethical guarantees, and the procedure of completing questionnaires were the same as those of Study 1 . All participants completed a questionnaire package including a 12-item version of the FAGQSE as well as additional scales measuring implicit theories of sports ability, perceived competence, and cognitive anxiety. The questionnaires were completed at the beginning of either sport sciences courses (athletes sample), compulsory PE lessons (PE sample), or training sessions (exercisers sample). A part of each sample had to complete the FAGQSE again 1 
month after the first completion (71 athletes: 32 males and 39 females, $M_{\text {age }}=23.3, S D_{\text {age }}=1.61 ; 46$ PE students: 27 males and 19 females, $M_{\text {age }}=15.5, S D_{\text {age }}=0.46 ; 15$ exercisers: 1 male and 14 females, $M_{\text {age }}=73.2, S D_{\text {age }}=5.79$ ).

\section{Measures}

Achievement goals were measured with a 12 -item version of the FAGQSE obtained after removing the two items with the lowest loadings from each scale (see Appendix). The instructions to be read before answering the questionnaire were adapted to the new two populations by replacing the word "sport" (athletes sample) with "physical education" (PE students sample) or "physical activity" (exercisers sample).

The implicit theories of sport ability were measured with the Conception of Sport Ability French Questionnaire (Sarrazin et al., 1995). This scale includes four items which address entity theory (e.g., "One has a certain level of ability in sport, and there is not much one can do to change it") and three items that address incremental theory (e.g., "If one works hard and often, one can change one's level of ability in sports"). The participants indicated their degree of agreement on a 5-point Likert-type scale ranging from 1 (completely disagree) to 5 (completely agree). The score of incremental theory and entity theory were calculated by averaging the scores of their corresponding items.

Participants' perceived level of competence in sports/PE/exercise setting was measured with the Perceived Competence subscale of the Scale of Satisfaction of the Fundamental Needs in Sport Context developed in French by Gillet, Rosnet, and Vallerand (2008). Five items such as "I often feel successful" were answered on a 4-point Likert-type scale ranging from 1 (not at all) to 4 (extremely). The score of perceived competence was calculated by averaging the scores of the 5 items.

The degree to which participants experienced cognitive anxiety in sports/PE/exercise settings was measured with the French version of Cox, Martens, and Russel's (2003) Competitive State Anxiety Inventory-2 Revised (CSAI2R), which was validated by Martinent, Ferrand, Guillet, and Gautheur (2010). Five items such as "I'm afraid to fail" were answered on a 4-point Likert-type scale ranging from 1 (not at all) to 4 (extremely). The score of anxiety was obtained by calculating the mean of the five answers.

\section{Data Analyses}

The same statistical tests as those of Study 1 (except AIC) were used to examine the qualities of the four-goal structure of the 12-item FAGQSE among the three samples of interest. Correlation analyses were used to examine the test-retest reliability of the questionnaire among the aggregated subsamples devoted to this purpose $(n=132)$ as well as the concurrent validity of the FAGQSE for the whole population.

\section{Results}

\section{Factorial Structure}

As shown in Table 3, NNFI and CFI indices and the $\chi^{2} / d f$ ratio of the four-goal structure of the 12-item FAGQSE were good for each sample and were better than in Study 1. The RMSEA index became good for PE students and remained acceptable for both athletes and exercisers. For the three samples, the upper bound of the $90 \%$ confidence interval of the RMSEA remained good, and the lower bound was better than in Study 1. However, while this lower bound was good for PE students and satisfactory for exercisers, it was only marginally acceptable for athletes.

As shown in Table 4, for the three samples, high positive interfactor and interscale correlations were found between the two mastery goals and between the two performance goals. For athletes and PE students, moderate positive correlations were found between the two avoidance goals and between mastery-approach and performance-avoidance goals. Moderate negative correlations were found between the two approach goals among exercisers, whereas among PE students, moderate positive correlations were found between the two approach goals and between mastery-avoidance and performance-approach goals. The items still loaded on their respective factors significantly $(p<.01)$ and highly, with coefficients $\beta$ ranging from .63 to .96 . The coefficients $\alpha$ remained good for all the samples $(.73<\alpha<.95)$.

\section{Test-Retest Reliability}

Significant positive test-retest correlations were found for mastery-approach goals $(r(131)=.55, p<.001)$; performance-approach goals $(r(131)=.68, p<.001)$; mastery-

Table 3. Fit indices for the four-goal structure of the 12-item FAGQSE used in different types of practice of physical activities

\begin{tabular}{|c|c|c|c|c|c|c|}
\hline Samples & $\chi^{2} / d f$ & NNFI & CFI & RMSEA & LO90 & HI90 \\
\hline Athletes $(n=270)$ & 2.77 & .99 & .99 & .081 & .065 & .098 \\
\hline Exercisers $(n=234)$ & 2.23 & .99 & .99 & .073 & .054 & .091 \\
\hline PE Students $(n=255)$ & 1.70 & .99 & .99 & .053 & .032 & .072 \\
\hline
\end{tabular}

Notes. NNFI = nonnormed fit index; $\mathrm{CFI}=$ comparative fit index; RMSEA = root mean square error of approximation; LO90 = Lower bound of the RMSEA's 90\% confidence interval; HI90 = Upper bound of the RMSEA's 90\% confidence interval. 
Table 4. Descriptive statistics, Cronbach's $\alpha$, and correlations matrix for the four-goal structure of the 12-item FAGQSE used in different types of practice of physical activities

\begin{tabular}{|c|c|c|c|c|}
\hline & 1 & 2 & 3 & 4 \\
\hline \multicolumn{5}{|l|}{ Athlete's sample $(n=270)$ : } \\
\hline$M$ & 4.63 & 2.91 & 4.22 & 3.10 \\
\hline$S D$ & 0.67 & 1.21 & 0.80 & 1.11 \\
\hline Mastery-approach goals & .88 & & & \\
\hline Performance-approach goals & $.05 / .04$ & .92 & & \\
\hline Mastery-avoidance goals & $.84 * / .70 *$ & $.12 / .09$ & .75 & \\
\hline Performance-avoidance goals & $.20 / .18^{*}$ & $.69 * / .62 *$ & $.42 * .34 *$ & .88 \\
\hline \multicolumn{5}{|l|}{ Exercisers' sample $(n=234)$ : } \\
\hline$M$ & 4.31 & 1.82 & 4.12 & 2.28 \\
\hline$S D$ & 1.01 & 1.25 & 0.98 & 1.31 \\
\hline Mastery-approach goals & .87 & & & \\
\hline Performance-approach goals & $.29 * / .25 *$ & .95 & & \\
\hline Mastery-avoidance goals & $.96 * / .79 *$ & $.17 / .14 *$ & .77 & \\
\hline Performance-avoidance goals & $.13 / .11$ & $.73 * .70 *$ & $.00 / .00$ & .89 \\
\hline \multicolumn{5}{|l|}{ PE Students' sample $(n=255)$ : } \\
\hline$M$ & 4.30 & 2.98 & 4.05 & 3.50 \\
\hline$S D$ & 0.82 & 1.38 & 0.86 & 1.14 \\
\hline Mastery-approach goals & .79 & & & \\
\hline Performance-approach goals & $.27 * / .22 *$ & .91 & & \\
\hline Mastery-avoidance goals & $.88 * / .69 *$ & $.32 * / .28$ & .73 & \\
\hline Performance-avoidance goals & $.52 * / .42 *$ & $.78 * .65 *$ & $.59 * / .46 *$ & .79 \\
\hline
\end{tabular}

Notes. Interfactor correlations are presented before the slash; interscale correlations are presented after the slash. * $p<.05$; Bold values in the diagonal represent Cronbach's $\alpha$.

avoidance goals $\left(r_{(131)}=.38, p<.001\right)$; and performanceavoidance goals $(r(131)=.48, p<.001)$ among the participants who completed the 12-item FAGQSE twice.

\section{Concurrent Validity}

The two kinds of mastery goals were positively related to incremental beliefs (mastery-approach: $r_{(758)}=.48, p<$ .001 ; mastery-avoidance: $\left.r_{(758)}=.40, p<.001\right)$ and perceived competence (mastery-approach: $r(758)=.19, p<$ .001 ; mastery-avoidance: $r(758)=.19, p<.001)$ and negatively related to entity beliefs (mastery-approach: $r_{(758)}=$ $-.27, p<.001$; mastery-avoidance: $\left.r_{(758)}=-.21, p<.001\right)$. The two kinds of performance goals were positively related to entity theory (performance-approach: $r_{(758)}=.13, p<$ .001 ; performance-avoidance: $r(758)=.10, p<.05)$ and to cognitive anxiety (performance-approach: $r_{(758)}=.27, p<$ .001 ; performance-avoidance: $r(758)=.29, p<.001)$.

\section{Discussion}

Reducing the FAGQSE to 12 items improved the fit indices of the four-goal structure of the instrument. The factorial structure of the 12-item version of the FAGQSE was found to be good for PE students and acceptable for athletes and exercisers. Again, consistent with previous findings (Elliot \& McGregor, 2001; Elliot \& Murayama, 2008), goals sharing either the same definition of competence or the same valence were found to be positively correlated, except the exercisers' two approach goals, which were linked by a surprising negative correlation. Whether the bipolarity of mastery-approach goals and performance-approach goals is specific to exercisers - here, a sample clearly older than the others and including mainly females - is to be examined in further research. Moreover, some unexpected positive correlations were found between goals that do not have common dimensions (i.e., mastery-approach and performance-avoidance for athletes and PE students; mastery-avoidance and performance-approach for PE students). Similar hardly explainable correlations were also found by Elliot and McGregor (2001) and by Elliot and Murayama (2008), for instance, between mastery-avoidance and performance-approach. The 12-item FAGQSE was theoretically valid since it was significantly linked to known goal-related constructs. Finally, its reliability ranged from moderate to satisfactory depending on the goals, with a particularly low test-retest correlation for mastery-avoidance. Achievement goals are generally stable when they are considered at the dispositional level, for instance, as achievement motives (e.g., Schultheiss, 2008). However, when achievement goals are considered in terms of specific intents - as in 
the present research - they are often found to vary more or less over time (Fryer \& Elliot, 2007) depending on the situation (Gernigon, d'Arripe-Longueville, Delignières, \& Ninot, 2004). This property may account for the various patterns of test-retest correlations that we observed.

\section{General Discussion}

The present research develops and validates a French questionnaire (FAGQSE) measuring achievement goals in sports and exercise settings. Compared to three-goal or different two-goal models, a four-goal model was found to better account for the factorial structure of the FAGQSE, which is consistent with similar research conducted in academics (Elliot \& Murayama, 2008). A noteworthy feature of the FAGQSE is its adaptability to different contexts of practice of sports and physical activities. This adaptability results from the specifications to a given context lying in the wording of the instructions, whereas the wordings of the items are context-free. As a result, the FAGQSE is a somewhat short instrument (12 items) that can be easily used to measure achievement goals with respect to different purposes such as athletes' preparation to performance, persons' adherence in exercise programs for health and wellbeing, and students' persistence in PE courses.

Despite its psychometrical qualities, the FAGQSE remains open to further improvements. As in previous research (Elliot \& McGregor, 2001; Elliot \& Murayama, 2008), we found that goals are nonorthogonal constructs, which may account for possible overlaps among their determinants and their consequences. Future research still needs to be conducted to identify the conditions under which the four achievement goals display specific explanatory powers. There is also a need to test whether the interfactor relationships display specificities depending on the very characteristics of the population. Therefore, as done in the past for the two-goal framework, the incremental validity of the present four-goal instrument should be further supported by showing its sensitivity to experimental conditions (e.g., Gernigon, d'Arripe-Longueville, Debove, \& Puvis, 2003) and to various significant others-induced goal-involving climates (Le Bars, Ferron, Maïano, \& Gernigon, 2006; Le Bars, Gernigon, \& Ninot, 2009).

The FAGQSE is a valid and reliable questionnaire that can already be used for research in various sports and exercise settings for both theoretical and applied purposes.

\section{Acknowledgments}

Thanks are due to Marie-Christine Cauvy, Aïna Chalabaev, Stéphanie Scoffier, and Paquito Bernard for their assistance as well as to the clubs, associations, and high schools that welcomed this investigation.

\section{References}

Chen, F., Curran P. J., Bollen, K. A., Kirby J., \& Paxton P. (2008). An empirical evaluation of the use of fixed cutoff points in RMSEA test statistic in structural equation models. Sociological Methods and Research, 36, 462-494.

Ciani, K. D., \& Sheldon, K. M. (2010). Evaluating the masteryavoidance goal construct: A study of elite college baseball players. Psychology of Sport and Exercise, 11, 127-132.

Conroy, D.E., Elliot, A. J., \& Hofer, S. M. (2003). A $2 \times 2$ achievement goals questionnaire for sport: Evidence for factorial invariance, temporal stability, and external validity. Journal of Sport and Exercise Psychology, 25, 456-476.

Corrion, K., d'Arripe-Longueville, F., Chalabaev, A., SchianoLomoriello, S., Roussel, P., \& Cury, F. (2010). Effect of implicit theories on judgment of cheating acceptability in physical education: The mediating role of achievement goals. Journal of Sports Sciences, 28, 909-919.

Cox, R. H., Martens, M. P., \& Russel, W. D. (2003). Measuring anxiety in athletics: The revised Competitive State Anxiety Inventory-2. Journal of Sport and Exercise Psychology, 25, 519-533.

Cury, F., Da Fonséca, D., Rufo, M., \& Sarrazin, P. (2002). Perceptions of competence, implicit theory of ability, perception of motivational climate, and achievement goals: A test of the trichotomous conceptualization of endorsement of achievement motivational in the physical education setting. Perceptual and Motor Skills, 95, 233-244.

Dweck, C. S. (1986). Motivational processes affecting learning. American Psychologist, 41, 1040-1048.

Dweck, C. S., \& Leggett, E. L. (1988). A social-cognitive approach to motivation and personality. Psychological Review, 95, 256-273.

Elliot, A. J., \& McGregor, H. A. (2001). A $2 \times 2$ achievement goal framework. Journal of Personality and Social Psychology, 80, 501-519.

Elliot, A. J., \& Murayama, K. (2008). On the measurement of achievement goals: Critique, illustration, and application. Journal of Educational Psychology, 100, 613-628.

Fryer, J. W., \& Elliot, A. J. (2007). Stability and change in achievement goals. Journal of Educational Psychology, 99, 700-714.

Gernigon, C., d'Arripe-Longueville, F., Debove, V., \& Puvis, A. (2003). Situational indexes of achievement motivation, helpseeking, and performance: Influences of the learning context and gender differences. Research Quarterly for Exercise and Sport, 74, 473-479.

Gernigon, C., d'Arripe-Longueville, F., Delignières, D., \& Ninot, G. (2004). A dynamical systems perspective on goal involvement states in sport. Journal of Sport and Exercise Psychology, $26,572-596$.

Gillet, N., Rosnet, E., \& Vallerand, R. J. (2008). Développement d'une échelle de satisfaction des besoins fondamentaux en contexte sportif [Development of a scale of satisfaction of the fundamental needs in sport context]. Canadian Journal of Behavioral Science, 40, 230-237.

Kline, R. B. (2005). Principles and practice of structural equation modeling. New York: Guilford.

Le Bars, H., Ferron, F., Maïano, C., \& Gernigon, C. (2006). Development and validation of the Significant Others Goal-Involving Roles in Sport Questionnaire. International Journal of Sport Psychology, 37, 359-380. 
Le Bars, H., Gernigon, C., \& Ninot, G. (2009). Personal and contextual determinants of elite young athletes' persistence or dropping out over time. Scandinavian Journal of Medicine and Science in Sports, 19, 274-285.

Martinent, G., Ferrand, C., Guillet, E., \& Gautheur, S. (2010). Validation of the French version of the Competitive State Anxiety Inventory-2 Revised (CSAI-2R) including frequency and direction scales. Psychology of Sport and Exercise, 11, 51-57.

McGregor, H. A., \& Elliot, A. J. (2002). Achievement goals as predictors of achievement-relevant processes prior to task engagement. Journal of Educational Psychology, 94, 381-395.

Nicholls, J. G. (1984). Achievement motivation: Conceptions of ability, subjective experience, task choice, and performance. Psychological Review, 91, 328-346.

Nunnally, J.C., \& Bernstein, I. H. (1994). Psychometric theory (3rd ed.). New York: McGraw-Hill.

Roberts, G. C., Treasure, D. C., \& Conroy, D.E. (2007). Understanding the dynamics of motivation in sport and physical activity: An achievement goal interpretation. In G. T. Tenenbaum \& R. C. Eklund (Eds.), Handbook of sport psychology (3rd ed., pp. 3-30). Hoboken, NJ: Wiley.

Sarrazin, P., Famose, J.-P., Biddle, S. J.H., Fox, K. R., Durand, M., \& Cury, F. (1995). Buts d'accomplissement et croyances relatives à la nature de l'habileté motrice [Achievement goals and beliefs about the nature of motor skill]. Science et Motricité, 26, 21-31.

Schiano-Lomoriello, S., Cury, F., \& Da Fonséca, D. (2005). Development and validation of the approach and avoidance questionnaire for sport and physical education setting (AAQSPE). European Revue of Applied Psychology, 55, 85-98.

Schultheiss, O. C. (2008). Implicit motives. In O.P. John, R. W. Robins, \& L. A. Pervin (Eds.), Handbook of personality: Theory and research (3rd ed., pp. 603-633). New York: Guilford.

Published online: December 15, 2011

François Riou

Laboratory Epsylon
University of Montpellier
4 boulevard Henri IV
34000 Montpellier
France
Tel. +33467 601-183
Fax +33467 415-708
E-mail francois.riou@ univ-montp1.fr

\section{Appendix}

Items of the French Achievement Goals Questionnaire for Sport and Exercise (FAGQSE)

\section{Mastery-Approach Goal}

*1. Mon objectif est de bien maîtriser ce que j'ai à faire. (My aim is to completely master what I have to do.)

5. Mon but est de progresser autant que possible. (My goal is to progress as much as possible.)

9. Je cherche à réaliser le mieux possible ce que je dois faire. (I am striving to carry out what I have to do as thoroughly as possible.)

13. Mon but est de m'améliorer le plus possible. (My goal is to improve as much as possible.)

*17. Je cherche à faire de mon mieux. (I am striving to do my best.)

Performance-Approach Goal

*2. Je cherche à faire mieux que les autres. (I am striving to do better than others.)

*6. Mon objectif est d'être bon(ne) comparé(e) aux autres. (My aim is to be good compared to others.)

10. Mon but est d'être meilleur(e) que les autres. (My goal is to perform better than others.)

14. Mon but est de surpasser les autres. (My goal is to outperform others.)

18. Je cherche à être au-dessus des autres. (I am striving to be superior to others.)
Mastery-Avoidance Goal

*3. Mon objectif est de ne pas être en-dessous de mes capacités. (My aim is to avoid performing below my capabilities.)

7. Je cherche à ne pas faire les choses à moitié. (I am striving to avoid doing things incompletely.)

*11. Mon but est d'éviter de faire moins bien que d'habitude. (My goal is to avoid doing worse than I usually do.)

15. Je cherche à éviter de mal faire les choses. (I am striving to avoid doing things badly.)

19. Mon but est d'éviter de faire des erreurs. (My goal is to avoid making mistakes.)

Performance-Avoidance Goal

*4. Mon but est d'éviter d'être mauvais(e) par rapport aux autres. (My goal is to avoid doing worse than others.)

8. Je cherche à éviter d'être moins bon(ne) que les autres. (I am striving to avoid being less good than others.)

12. Je cherche à éviter d'être en-dessous des autres. (I am striving to avoid being inferior to others.)

16. Mon objectif est d'éviter de faire moins bien que les autres. (My aim is to avoid performing worse than others.)

*20. Mon but est de ne pas être surpassé(e) par les autres. (My goal is to avoid being outperformed by others.)

Note. *Items 1, 2, 3, 4, 6, 11, 17, and 20 were dropped and do not belong to the final model. 